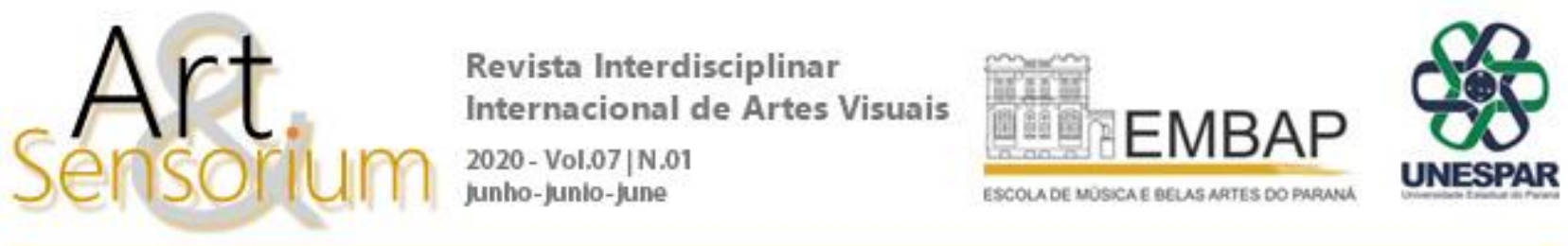

\title{
DE SPECTATOR A ESPECTADOR: REPENSANDO A INTERFACE ENTRE A EMANCIPAÇÃO NAS ARTES E NA EDUCAÇÃO
}

\author{
DOI: https://doi.org/10.33871/23580437.2020.7.1.28-43
}

Vinicius B. Vicenzi ${ }^{1}$

\begin{abstract}
Resumo: Este artigo busca repensar a interface entre a emancipação nas artes e na educação a partir da análise do conceito de espectador. Revisita a origem latina de spectator, mostrando as diferenças frente ao theorós grego. Promove, assim, uma espécie de genealogia do conceito na tentativa de repensar o estatuto de passividade frente ao agir e ao conhecer. Para isso, apoia-se na análise que Jacques Rancière faz em $O$ espectador emancipado sobre os modelos de eficácia da arte, traçando paralelos entre aquilo que o filósofo define como mediações pedagógicas nas artes para pensar sua interface com o universo da educação, redefinindo, também, um certo lugar para a filosofia da educação. Tais razões ganham consistência no seio das partilhas do sensível que delimitam uma certa relação de oposição entre o olhar e o conhecer, o olhar e o agir, partilhas que incidem também, por consequência, no modo de ser aluno. Pensar a emancipação em sintonia com o universo estético e, também, da filosofia política, no sentido de uma emancipação intelectual, permitem, assim, propor junto com Rancière um paralelismo entre o espectador emancipado e o aluno emancipado. Não mais nos termos de lugares de passividade e que, para tanto, necessitariam ser reformados. A reforma do teatro via espectador ou a reforma de escola via aluno são faces de um mesmo dispositivo de poder, de uma mesma partilha do sensível. Repensar a interface entre a emancipação nos contextos das artes e da educação pode nos permitir um novo olhar sobre estas figuras, tradicionalmente encerradas em utopias políticas que as viam apenas como dispositivos em potência, jamais em ato, ensejando uma nova forma de compreendermos o lugar da educação como questão filosófico-política e estética.
\end{abstract}

Palavras-chave: espectador; emancipação; partilha do sensível; aluno; filosofia da educação.

\section{FROM LATIN SPECTATOR TO MODERN SPECTATOR: RETHINKING THE INTERFACE BETWEEN EMANCIPATION IN ARTS AND EDUCATION}

\begin{abstract}
This article seeks to rethink the interface between emancipation in arts and education through the analysis of the spectator concept. It revisits the Latin origin, showing its differences from the Greek theorós. It thus promotes a kind of genealogy of the concept in an attempt to rethink its

\footnotetext{
${ }^{1}$ https://orcid.org/0000-0001-8208-2131. Universidade Federal de Santa Catarina - Florianópolis - SC - Brasil. E-mail: viniciusvicenzi@gmail.com. Currículo: Professor do Departamento de Estudos Especializados em Educação da Universidade Federal de Santa Catarina (UFSC). Doutor em Filosofia pela Universidade do Porto (Portugal), com intercâmbio à Université Paris IV - Sorbonne (Erasmus 2013/2014). Mestre em Educação pela Universidade do Estado do Rio de Janeiro (UERJ). Bacharel e Licenciado em Filosofia pela Universidade Federal de Santa Catarina (UFSC). Pesquisa as relações entre educação, estética e filosofia política na obra do filósofo francês Jacques Rancière. Membro do Núcleo de Estudos de Filosofia e Infância (NEFI/UERJ), do Aesthetics, Politics and Art Research Group, do Instituto (LEFIS/UFSC).
} de Filosofia da Universidade do Porto (Portugal) e do Laboratório Interdisciplinar de Ensino de Filosofia e Sociologia
\end{abstract}


status of passivity against acting and knowing. To this end, it is based on Jacques Rancière's analysis in The emancipated spectator on models of art effectiveness, drawing parallels between what the philosopher defines as pedagogical mediations in arts to think their interface with the universe of education, also redefining a certain place for philosophy of education. Such reasons gain consistency within the distribution of the sensible that delimit a certain relationship of opposition between view and knowledge, view and act, shares that also affect, consequently, the way of being a student. Thinking of emancipation in tune with the aesthetic universe and, also, of political philosophy, in the sense of intellectual emancipation, thus allow to propose, along with Rancière, a parallelism between the emancipated spectator and the emancipated student. No more in terms of passive places, which would need to be reformed. The reform of the theatre via spectator or the reform of school via student are faces of the same power device, the same distribution of the sensible. Rethinking the interface between emancipation in arts and education contexts can give us a new look at these figures, traditionally enclosed in political utopias that saw them only as potential devices, never in action. It gives rise to a new way of comprehending the place of education as a philosophical-political and aesthetical issue.

Keywords: spectator; emancipation, distribution of the sensible; student; philosophy of education.

Resumen: Este artículo busca repensar la interfaz entre la emancipación en las artes y la educación a través del análisis del concepto de espectador. Vuelve al origen latino del espectador, mostrando las diferencias con el griego theorós. Por lo tanto, promueve un tipo de genealogía del concepto en un intento de repensar el estado de pasividad al actuar y conocer. Con este fin, se basa en el análisis que Jacques Rancière hace en Lo espectador emancipado sobre los modelos de eficacia de las artes, trazando paralelos entre lo que el filósofo define como mediaciones pedagógicas en las artes para pensar sobre su interfaz con el universo de la educación, redefiniendo así cierto lugar para la filosofía de la educación. Tales razones ganan coherencia dentro de las partages de lo sensible que delimitan una cierta relación de oposición entre la mirada y el conocimiento, la mirada y el acto, acciones que también afectan, en consecuencia, la forma de ser un estudiante. Pensar en la emancipación en sintonía con el universo estético y, también, con la filosofía política, en el sentido de la emancipación intelectual, permite proponer, junto con Rancière, un paralelismo entre el espectador emancipado y el estudiante emancipado. No más en términos de lugares pasivos, que tendrían que ser reformados. La reforma del teatro a través del espectador o la reforma de la escuela a través del estudiante son caras del mismo dispositivo de poder, de la misma partage de lo sensible. Repensar la interfaz entre la emancipación en el contexto de las artes y la educación puede darnos una nueva mirada a estas figuras, tradicionalmente encerradas en utopías políticas que las veían solo como dispositivos potenciales, nunca en acción, dando lugar a una nueva forma de entender el lugar de la educación como cuestión filosófica - política y estética.

Palabras Clave: espectador; emancipación; partage de lo sensible; estudiante; filosofia de la educación.

A passagem do theorós grego para o spectator latino, de onde surgirá o nosso espectador nos guarda algumas surpresas. A principal delas é que, como afirma o Dictionnaire historique de la langue française (2006), de Rey, a palavra espectador [spéctateur] "usada somente para homens até o século XVI [...] para designar a testemunha de um evento, de uma ação, em concorrência com a observação [...], palavra que desaparece nesse sentido em meados do século XVII" (REY. 2006, p. 3613 tradução nossa) passa a ter, a partir da Renascença "o sentido de «pessoa que assiste a um espetáculo» e designa, em particular, a pessoa que observa uma ação sem participar dela.” (REY, 2006, p. 3613 tradução nossa). No século XVIII passará a designar também, por extensão, "a pessoa imaginária tida como referência ao descrever um conjunto espacial” (REY, 2006, p. 3613 - tradução nossa). A 
passagem do theorós ao spectator permitiu-nos, então, passar de um universo amplo da visão para um uso bastante específico, sendo-nos bastante incomum hoje pensar o espectador para fora da sua função passiva de alguém que somente observa. O sentido ativo da theoria grega, de alguma forma, se perdeu.

Parte, talvez, dessa mutação já se inicia, todavia, com os latinos ao serem os primeiros a separar spectator e theoria. Lembremos que theoria mantém-se como palavra latina e designa tão somente a especulação, a pesquisa especulativa, num prosseguimento, assim, das indicações que já apareciam desde Platão e, sobretudo, de Aristóteles e que ganham ainda mais evidência no helenismo. Esse sentido de theoria latina como especulação aparece, por exemplo, nos Commentarii in Ezechielm prophetam $(12,40)$, de Hieronymus [séc IV-V] ou nas Collationes $(14,2)$, de Cassianus [séc. V]. Spectator, por sua vez, designa "aquele que olha, que observa", "observador", "contemplador", no sentido de observador do céu e dos astros, como na Ab Urbe condita libri (24,34,2), de Tito-Lívio [séc. I a.C-I d.C], ou no De Natura deorum librii, de Cícero [séc. II a.C - I a.C]. Também num sentido específico de "espectador, testemunha", como no De oratore $(1,24,112)$, de Cícero; ou no De officis $(2,7,26)$, também de Cícero. Tito-Lívio, no já citado Ab Urbe condita librii $(1,28)$, também se utiliza, assim, do termo. Num sentido, contudo, mais específico, que nos será cada vez mais comum, como "espectador de teatro", já aparece em Plauto, por exemplo, na cena final do Anfitrião (5,3,3). Também nas cenas finais de Cistellaria (4,2,9 - 785 na versão da Belles-Lêtres), de Pseudolus (2,4,30 - 1332), ou de Stichus $(5,3,1-775)$, sempre com o mesmo sentido de convocar os espectadores a aplaudirem. Cícero, também, em De haruspicum responsis $(11,22)$, faz uso semelhante.

Um quarto sentido de spectator é, ainda, o de examinador, juiz, crítico, ou como preferem a tradução francesa e portuguesa, conhecedor. É assim que aparece, por exemplo, na peça $O$ Eunuco, de Terêncio [II a.C.]. Também Tito-Lívio, no seu Arb Urbe condiita $(42,34,7)$ faz uso de spectator em sentido semelhante.

Temos, então, quatro sentidos principais que os latinos conferiram a espectador: aquele que olha/contemplador, testemunha, espectador teatral e examinador/crítico/conhecedor, todos sentidos não muito distantes da tradição grega. É interessante constatar, contudo, que a passagem de theorós para spectator revela uma mudança forte de raiz. Enquanto theorós guarda uma raiz muito próxima ao theós grego, às festas religiosas às quais esses observadores eram enviados, spectator traz consigo uma raiz que, ainda que não totalmente distante dessa esfera, já que era usada como segundo termo em compostos preservados pela linguagem religiosa, como auspicioso, por exemplo, não a traz tão presente $^{2}$, o que ao longo dos anos a tornaria cada vez mais distante dessa noção.

É interessante o modo como essa raiz se aproxima de um campo ligado às imagens, formando, por exemplo, spectrum que seria a versão latina do eidolon grego, ou speculum, espelho. Essa aproximação é garantida, segundo Ernout e Meillet (1959), também, a partir de composições com specio

no sentido de «ver» através dos olhos, foi acrescentada uma nuance de sentido moral; também em despicio «olhar de alto a baixo» [...] prospicio «olhar à frente» $\mathrm{e}$ «planejar» [...] respectus, «consideração, respeito» [...] suspicio «levantar a cabeça para olhar» $[\ldots]$ inspicio «olhar dentro» e «examinar, estudar» (ERNOUT; MEILLET, 1959, p. 639 - tradução nossa.)

O que parece estar em jogo, portanto, é uma certa relação com o ver, ou melhor, uma relação com o que é visto, com a imagem. A noção de espectador vai gradativamente, já desde os Gregos, passando

\footnotetext{
${ }^{2}$ Segundo Ernout e Meillet (1959), a palavra spectator deriva de uma raiz spek'-, cuja "proximidade de sentido e de formas tornam difícil de descartar a ideia de que o grupo do gr. sképtomai [...] «observo» resultaria de uma metátese de *spek'- en *skep-" (1959, p. 640). Esse grupo (specio, spexi, spectum, specere) formam, assim, um mesmo conjunto semântico ligado ao perceber, ao olhar, mas que, segundo Ernout e Meillet (1959) possuem uma "sensação de artifício" (ERNOUT; MEILLET, 1959, p. 639 - tradução nossa).
} 
de uma noção em que o sentido ativo/passivo do olhar era presente para uma noção cada vez mais passiva, baseada sobretudo na imagem. A depender, assim, da consideração das imagens, e não é à toa que Rancière tenha se dedicado tanto nos últimos anos a pensar a imagem, como em Le destin des images (2003) e Le spectateur émancipé (2008), teremos uma avaliação A ou B a respeito dos espectadores e, consequentemente da relação entre ver e agir. É interessante, por exemplo, ver que um dos sentidos de species, ao lado de vista, é aspecto/aparência, como o que "se opõe à res, «realidade»" (1959, p. 640 - tradução nossa). Isso que a um grego seria um pouco difícil de pensar, isto é, pensar o espectador como "falso/pretensão, pretexto" (ERNOUT; MEILLET, 1959, p. 640 tradução nossa), parece muito mais fácil a um latino e a todos nós que derivamos das línguas latinas.

Se é verdade que Platão já via nas imagens, na mimesis teatral, elementos de uma teatrocracia perigosa, ${ }^{3}$ parece-nos que a sua implicância com as imagens deriva mais da impossibilidade de aquele que as emite poder falar em nome próprio, fala como um duplo, do que propriamente numa consideração da falta de realidade das imagens como um todo. Se é certo que Platão faz um filtro ético por onde as imagens devem passar, por outro lado não as elimina por completo de sua consideração. Não é à toa que há tantos mitos em Platão, que a alma que filosofa faz theoria, que o homem que sai da caverna, vê, contempla. E contempla eidos, contempla idéa, contempla formas ou aspectos. Nesse sentido, ainda que seja inegável que o processo se inicia com a filosofia platônica, a própria palavra theoria é muito mais equívoca para o sentido que Platão e Aristóteles passam a empregar do que spectator. Como os gregos só possuíam uma palavra para espectador e para teoria, isso a torna muito mais indeterminada do que quando essas duas noções se distinguem completamente. O sentido latino, portanto, de spectator nos ajuda, assim, a pensar essa separação e suas implicações.

\section{Sentido de espectador em Ranciére}

Uma vez analisada essa herança grega do termo theorós e de sua transliteração latina (spectator), bem como dos sentidos com os quais se viu atrelado desde então, sobretudo a partir do cunho aristotélico, parece poder fazer sentido repensarmos o papel do espectador. Le spectateur émancipé (2008), nos dá algumas indicações de como o conceito de espectador pode ser determinante para pensarmos a nossa relação com o saber e com o agir, implicações estas fundamentais para repensarmos o lugar da educação. É certo que Rancière não procede a uma análise etimológica do termo espectador, buscando suas origens gregas. Parte, sobretudo, de um contexto estético-político contemporâneo e o pensa à luz do pensamento platônico e aristotélico sobre as imagens e as artes, a partir do conceito de mimese. Nesse sentido nos conta que a posição do espectador é denegada historicamente por duas razões principais: o conhecer e o agir. Razões que ganham consistência no seio das partilhas do sensível que delimitam uma certa relação de oposição entre o olhar e o conhecer, o olhar e o agir, partilhas que incidem também, por consequência, no modo de ser aluno.

Em primeiro lugar o olhar é contrário de conhecer. O espectador permanece face a uma aparência, ignorando o processo de produção dessa aparência ou a realidade que a aparência encobre. Em segundo lugar, o olhar é o contrário de agir. A espectadora fica imóvel no seu lugar, passiva. Ser espectador é estar separado ao mesmo tempo da capacidade de conhecer e do poder de agir (RANCIÈRE, 2010b, p. 8-9)

Só podemos entender a primeira parte da acusação, a que incide sobre a relação entre olhar e conhecimento, se já tivermos como comum a ideia de que olhar uma imagem é olhar uma cópia já infiel da realidade, uma cópia da cópia, se já tivermos fixado o olhar como o olho, "uma máquina de ignorância, uma máquina óptica que forma os olhares para a ilusão e para a passividade" (2010, p.

3 Cf. PLATÃO, 700d-701a. 
9); se já tivermos presente, portanto, as considerações platônicas a respeito da imagem, o regime ético das imagens. ${ }^{4}$ Se nos fiarmos à história antiga, pré-platônica, do conceito de espectador veríamos um outro cenário, em que o espectador não só está ligado ao conhecer como sua primeira manifestação, como afirma o crítico literário Wlad Godzich $(1989)^{5}$, mas também ao agir, uma vez que, como bem mostra Villacèque (2013), a democracia grega, em sua ação política, pressupunha mesmo a função de espectador que os cidadãos possuíam, sejam sentados na ekklesia, sejam sentados no théatron.

A segunda parte da acusação ao espectador, a que versa sobre a oposição entre o olhar e o agir ganha sentido a partir do pressuposto de uma partilha do sensível que faz da mimesis representação. É desde um modelo pedagógico da eficácia da arte, ${ }^{6}$ da mediação representativa, que se pode pensar o direcionamento de uma ação, por exemplo, o desprezo à hipocrisia, a partir da visão de um espetáculo como $O$ Tartufo, de Moliére. A desconfiança dessa ligação direta só pode advir mediante a pressuposição de tal partilha.

O que o regime representativo da arte efetua é uma passagem da consideração da ação para o primeiro plano da reflexão sobre o teatro. É o drama quem ganha força em detrimento das imagens, do ser das imagens, objeto da crítica platônica. É na oposição entre a ação do drama e a ação política que se pode entender a oposição entre olhar e agir.

Se a consequência política da acusação ao espectador foi, em primeiro lugar, a extinção do teatro, a consequência prevalecente foi a de reformar o espectador, reformar o espectador para

um outro teatro, um teatro sem espectadores: não um teatro que se desenrole perante assentos vazios, mas um teatro em que a relação óptica passiva implicada pela própria palavra seja submetida a uma outra relação, aquela que está implicada numa outra palavra, a palavra que designa o que se produz em cena, o drama (RANCIÈRE, 2010b, p. 10).

Voltamos, portanto, sobre a partilha do sensível do regime representativo da arte, ${ }^{7}$ voltamos a Aristóteles. A reforma do espectador é a reforma da relação entre o olhar e o agir. A consequência política mais presente da crítica ao espectador é encenada, portanto, dentro da partilha do sensível do regime representativo, mesmo na sua tentativa crítica. ${ }^{8}$

O teatro é o lugar onde uma acção é conduzida ao seu acabamento por corpos em movimento frente a corpos vivos que se trata de mobilizar. Estes últimos podem ter renunciado ao seu poder. Mas este poder é retomado, reactivado na performance dos primeiros, na inteligência que constrói essa performance, na energia que ela produz. (RANCIÈRE, 2010b, p. 10)

O efeito presumido da mimese teatral é a ação, ainda que esta esteja despotencializada. Nisso Aristóteles não estaria muito distante da tradição democrática grega, segundo Villacèque. ${ }^{9}$ Reformar o espectador é, dessa forma, reformar a sua potência de agir. A condutibilidade que tal partilha do sensível opera é a que pressupõe a ação por meio da ação de outrem. É um efeito pedagógico comum,

4 Cf. RANCIÈRE, 2000, p. 27.

5 “em grego [theoria, o coletivo de theorós, de espectadores, portanto], não entra em oposição com práxis - uma oposição construída na filosofia idealista e mais tarde utilizada para combater esta última - mas antes com aesthesis" (GODZICH, Prefácio In: DE MAN, 1989, p. 14). O problema do conhecimento, então, estava resolvido "até que os filósofos chegaram e tentaram fundamentar tudo na percepção dos sentidos, na estese, com uma teorização muito sua, apropriada da pólis, por vias ainda pouco compreendidas, como única mediação” (GODZICH, Prefácio In: DE MAN, 1989, p. 16).

6 Cf. RANCIÈRE, 2008, p. 56-92.

7 Cf. RANCIÈRE, 2000, p. 30.

8 Cf. RANCIÈRE, 2009, p. 620.

9 Cf. VILLACÈQUE, 2013, p. 268-273.

R. Inter. Interdisc. Art\&Sensorium, Curitiba, v.7, n.1, p. 028 - 043 Jan.- Jun. 2020 
uma de suas mais arraigadas crenças: pensar que a performance de alguém, dos professores, por exemplo, na intencionalidade de suas inteligências, deve tratar de mobilizar esses que dela estão diante, os alunos. O caráter pedagógico de tal partilha é central no deslocamento do foco da imagem para a ação. A permanência do teatro se dá "sem espectadores, no qual quem assiste aprenda, em vez de ser seduzido por imagens" (RANCIÈRE, 2010b, p. 10 - grifo nosso). O teatro como um lugar de aprendizagem, ${ }^{10}$ o que de certa forma recupera a primeira acusação do espectador (a oposição entre o olhar e o conhecer), adquire, segundo Rancière, duas grandes fórmulas: o teatro épico de Brecht e o teatro da crueldade de Artaud. Fórmulas que nos parecem semelhantes às encontradas também pela pedagogia.

De acordo com a primeira, é necessário arrancar o espectador ao embrutecimento do papalvo fascinado pela aparência e conquistado pela empatia, que faz com que ele se identifique com as personagens em cena. Mostrar-se-lhe-á, portanto, um espectáculo estranho, inusual, um enigma cujo sentido ele deverá procurar. Deste modo forçá-lo-emos a trocar a posição de espectador passivo pela de alguém que conduz uma investigação ou uma experiência científica, alguém que observa os fenómenos e investiga as respectivas causas. Ou então propor-se-lhe-á um dilema exemplar, semelhante aos que se colocam aos indivíduos empenhados em decisões de acção. Far-se-á, assim, com que aguce o seu próprio sentido de avaliação das razões, da respectiva discussão e da escolha radical (RANCIÈRE, 2010, p. 11 - grifo nosso).

Essa primeira fórmula poderíamos traduzir como uma fórmula pedagógica da investigação, da procura de sentido. Propor um problema e pedir que o decifre. A reforma do espectador por esse viés é, assim, um reforço da distância que separa o aluno do conhecer, que o faz buscar a supressão dessa distância, daí o seu caráter mais ativo nessa metodologia de ensino. Toda análise da Escola Nova a esse respeito e toda discussão subsequente revelam aqui o seu sentido.

Uma segunda fórmula é a de Artaud:

De acordo com a segunda fórmula, é precisamente essa distância argumentante que deve ser abolida. $\mathrm{O}$ espectador deverá ser subtraído à posição de observador que examina calmamente o espectáculo que lhe é proposto. Deverá ser desapossado desse domínio ilusório e arrastado para dentro do círculo mágico da acção teatral onde trocará o privilégio de observador racional pelo de um ser na posse das suas energias vitais integrais. (RANCIÈRE, 2010, p. 11 - grifo nosso)

Essa segunda fórmula poderíamos traduzir como uma pedagogia da ação, em que a aprendizagem se dá pela própria ação, pela profundidade da imersão no objeto dado, numa espécie de comunhão. Ainda que essa fórmula seja um pouco menos usual que a primeira na tradição pedagógica, é ainda possível ouvir o seu eco. Ao invés de se reforçar a distância, nesse caso é o movimento inverso que acontece. Trata-se de "perder toda a distância" (RANCIÈRE, 2010, p. 11), de "abdicar da própria posição de mero sujeito do olhar" (RANCIÈRE, 2010, p. 12). Deve agir diretamente, compartilhar a ação, numa espécie de grande comunhão energética, de um grande impacto sensível diante da própria performance coletiva. As perspectivas contemporâneas de uma metodologia de ensino baseada em dinâmicas de grupo corporais, por exemplo, também parecem comungar do mesmo princípio.

A oscilação, assim, entre o teatro da "indagação distante" e o da "participação vital", por mais paradoxal que possa parecer, ao tentar manter o espaço da mimese teatral ao mesmo tempo em que repensava a função da mediação representativa, acabam retomando "não apenas os considerandos da

10 Cf. RANCIÈRE, 2003, p. 173. 
crítica platônica, mas também a fórmula positiva que Platão opunha ao mal teatral" (RANCIÈRE, 2010 , p. 12), a saber, "uma outra comunidade, epitomizada numa outra performance dos corpos" (RANCIÈRE, 2010, p. 12 - grifo nosso). Se para Platão essa comunidade era a própria república, para os reformadores do teatro via reforma do espectador essa comunidade é já o próprio teatro, quando este não é meramente espetáculo. ${ }^{11}$ Modificaram, assim, "a oposição platónica entre khoreia e teatro, transformando-a em oposição entre a verdade do teatro e o simulacro do espetáculo" (RANCIÈRE, 2010, p. 12 - grifo nosso).

A crítica de Debord ao espetáculo, ${ }^{12}$ por exemplo, deriva em grande parte dessa oposição, já que ainda que se sustente na interpretação de Marx da crítica de Feuerbach sobre a religião, esta depende da concepção platônica de mimese. ${ }^{13}$ Assim como Platão queria transformar a comunidade democrática ignorante em uma "comunidade coreográfica na qual ninguém permanece espectador imóvel, na qual cada um deverá mover-se pela proporção matemática" (RANCIÈRE, 2010b, p. 12 - grifo nosso), assim também os reformadores do teatro quiseram transformar o público passivo no seu contrário: “o corpo activo de um povo pondo em acto o seu princípio vital” (RANCIÈRE, 2010b, p. 12).

O mesmo deslocamento parece ocorrer, também, no cenário da sala de aula, em que os alunos, de público passivo passaram a ser tomados por seres ativos na expressão de um povo em seu aspecto potencial, na esperança teleológica do que podemos ser enquanto coletividades. Talvez um dos grandes legados da Revolução Francesa seja realmente essa proximidade entre teatro e educação, entre espectador e acontecimento. Não é à toa que Michelet fale, em pleno século XIX, de um "teatro do povo" como o que resumia "toda a educação das gloriosas cidades antigas". ${ }^{14} \mathrm{Kant}$, em seu O conflito das faculdades (1798), talvez seja, contudo, o primeiro a salientar a ideia do espectador como potência de ação, algo que a educação moderna transporá ao aluno. ${ }^{15}$

Não nos parece fortuito que a ideia do "teatro do povo" novecentista

fez-se corpo com o grande projeto da Educação Nacional e todos os destaques dessa ideia e do combate progressista a colocarão em evidência: o Império Liberal de Émile Ollivier e Victor Furuy; a República laica dos anos 80; a República dos anos 1900; e, após cada guerra mundial, o sopro da reconstrução e da Resistência. A cada vez reaparecia com evidência a necessidade de um meio suplementar de educação e de unidade nacionais, do enraizamento de letrados no seio do povo e de participação do povo nas riquezas da cultura. (RANCIÈRE, 2003b, p. 177-178 - tradução nossa).

A análise, assim, que Rancière faz a respeito do teatro brechtiano, poderíamos tomá-la, creio, como dizendo respeito à sala de aula, com a ressalva de que esta, por seu caráter geracional é em potência o que o teatro representa em ato, ou seja, que ela se configura como uma preparação para o estágio social da maturidade que o teatro representaria à comunidade: "O teatro é uma assembleia na qual as gentes do povo tomam consciência da sua situação e discutem os seus interesses" (RANCIÈRE, 2010b, p. 13). Poderíamos mesmo, analogamente, dizer: a sala de aula é uma assembleia na qual as gentes do povo tomam consciência da sua situação e discutem os seus interesses. Certamente

\footnotetext{
11 “O longo hábito dos espetáculos de entretenimento nos fez esquecer a idéia de um teatro grave que, abalando todas as nossas representações, insufle-nos o magnetismo ardente das imagens e acabe por agir sobre nós a exemplo de uma terapia da alma cuja passagem não se deixará mais esquecer” (ARTAUD, 1999, p. 96 - grifo nosso).

${ }^{12}$ Cf. DEBORD, 1967.

13 "E sem dúvida, nosso tempo [... prefere a imagem à coisa, a cópia ao original, a representação à realidade, à aparência ao ser..." (FEUERBACH apud DEBORD, 1992, p. 14 - tradução nossa).

${ }^{14}$ Cf. RANCIÈRE, 2003, p. 167-201.

${ }^{15}$ Cf. KANT, 2008, p. 104.
} 
teríamos o consentimento de inúmeros pedagogos relevantes. Paulo Freire, por exemplo, possivelmente concordaria com essa definição de sala de aula. ${ }^{16}$

De forma semelhante, então, poderíamos propor um paralelismo entre teatro e escola e espectadores e alunos quando Rancière afirma que

o teatro acusa-se a si mesmo de tornar os espectadores passivos e de assim trair a sua essência de acção comunitária. Como consequência outorga-se a missão de inverter os seus efeitos e de expiar os seus erros, devolvendo aos espectadores a posse da consciência e da atividade que lhes cabe (RANCIÈRE, 2010b, p. 15).

Tornou-se comum a crítica da escola nesse mesmo sentido: a escola acusa-se a si mesma de tornar os alunos passivos e de assim trair a sua essência de ação comunitária. Como consequência outorgase a missão de inverter os seus efeitos e de expiar os seus erros, devolvendo aos alunos a posse da consciência e da atividade que lhes cabe.

É preciso, então, o reexame de uma rede de pressupostos, equivalências e oposições que sustentam os princípios da crítica platônica que paradoxalmente a reforma do espectador reatualiza. São estes:

equivalências entre público teatral e comunidade, entre olhar e passividade, exterioridade e separação, mediação e simulacro; oposições entre o colectivo e o individual, entre a imagem e a realidade viva, a atividade e a passividade, a posse de si e a alienação" (RANCIÈRE, 2010b, p. 15).

O teatro passou a assumir para si uma tarefa pedagógica e, como paradigma para as artes, transmitiulhes esse efeito de "ensinar aos seus espectadores os meios de deixarem de ser espectadores e de se tornarem agentes de uma prática colectiva" (RANCIÈRE, 2010b, p. 15 - grifo nosso).

Através de uma metodologia de ensino brechtiana "a mediação teatral torna-os conscientes da situação social que dá lugar a essa mesma mediação, e desencadeia neles o desejo de agir para transformar a dita situação social" (RANCIÈRE, 2010, p. 15-16). Através de uma metodologia artaudiana os espectadores "em vez de estarem perante um espectáculo, são envolvidos pela performance, arrastados para dentro do círculo da acção que lhes devolve a sua energia colectiva" (RANCIÈRE, 2010b, p. 16). Por um viés ou por outro temos por consequência que a reformulação da mediação da representação teatral, devedora da partilha do sensível do regime representativo das artes, tende para a própria supressão da mediação, o que permite a Rancière colocá-la no seio da crítica à lógica pedagógica que a emancipação intelectual opera em Le Maître ignorant (1987).

A relação pedagógica se baseia justamente no papel entregue ao professor de "suprimir a distância entre o seu saber e a ignorância do ignorante" (RANCIÈRE, 2010b, p. 16), efeito de toda sua atividade de explicações. O problema está, como vemos com Jacotot, que essa supressão só se efetua mediante a sua recriação constante, pois só o professor é capaz de estabelecer onde inicia e onde termina uma explicação e, ao terminá-la, mostrar que o aluno, "pelo simples jogo das posições ocupadas" (RANCIÈRE, 2010, p. 17), ainda tem um próximo passo a percorrer, o passo da próxima lição, do próximo capítulo, livro, da próxima série, do próximo nível de estudo e, assim, indefinidamente enquanto permanecer na condição de aluno, enquanto persistir numa relação pedagógica. Na lógica desta "o ignorante não é apenas aquele que ignora o que o mestre sabe. É antes aquele que não sabe o que ignora nem como chega a saber isso que ignora" (RANCIÈRE, 2010b, p. 16). O que permanece sempre com o professor é o saber como fazer de algo ignorado objeto de saber, em que momento e segundo que protocolo. É o saber da criação, da intencionalidade, o mesmo operante nos artistas. O saber do ignorante, aquilo que ele descobre segundo a regra que soma o que já sabe com o desconhecido, regra democrática que faz da ignorância um menor saber, é agora substituído, a partir

${ }^{16}$ Cf. FREIRE, 1982, p. 82. 
do protocolo de transmissão do saber, por uma outra coisa: a ignorância não é mais um menor saber, é antes o oposto do saber. Eis a primeira lição de ser aluno.

O que a prática emancipadora do mestre ignorante Jacotot mostra, pelo contrário, ao ignorar o saber da língua que os alunos conheciam, o holandês, é que a ignorância da distância entre a ignorância do aluno e o saber do mestre "não é um mal a abolir, é antes a condição normal de toda a comunicação" (RANCIÈRE, 2010b, p. 19). Somos "animais distantes que comunicam através da floresta dos signos" (RANCIÈRE, 2010b, p. 19). O princípio da igualdade das inteligências só nos mostra isso:

o animal humano aprende todas as coisas como começou por aprender a língua materna, como aprendeu a aventurar-se na floresta das coisas e dos signos que o rodeiam, para assim tomar lugar entre os humanos: observando e comparando uma coisa com outra, um signo com um facto, um signo com outro signo (RANCIÈRE, 2010b, p. 18).

Suprimir a distância não pode significar, assim, suprimir a distância entre duas coisas préestabelecidas, aquilo que o aluno desconhece e aquilo que o professor sabe, que, na lógica embrutecedora, é uma e mesma coisa: o aluno deve aprender aquilo que o professor ensinou, aquilo que explicou, e nada além. O que está em jogo aqui, para a pedagogia, como estará também para as artes, e, diríamos, também para a política, é o direcionamento da supressão da distância. Tanto em Brecht como em Artaud há um fim pré-concebido para onde a supressão da distância espectador-ator deve levar. ${ }^{17}$ Não é mais o abismo entre os saberes, sabidos pelo autor, professor ou dramaturgo, e obviamente desconhecidos pelos alunos e pelo espectador. É o caminho entre o já sabido pelos alunos-espectadores e desconhecido pelos professores-dramaturgos (a sua aventura intelectual até então) e o que todos ignoram, aquilo que vier a aprender na sua relação com o já sabido.

O que está em jogo na partilha do sensível do regime ético das imagens que tortuosamente o teatro épico de Brecht e o da crueldade de Artaud reencontram é uma distribuição muito clara e cara dos papéis de quem pode ensinar e de quem deve aprender, da posição daquele que sabe. É nesse sentido que se pode deslocar a questão da aprendizagem para o campo da linguagem e não mais do saber. $\mathrm{O}$ aluno de Jacotot

pode aprender não para passar a ocupar a posição do sábio [algo que a relação pedagógica desautoriza por princípio - não se pode ser professor de seu professor naquilo que este leciona], mas para melhor praticar a arte de traduzir, a arte de pôr as suas experiências em palavras e as suas palavras à prova, de traduzir as suas aventuras intelectuais para uso dos outros e de voltar a traduzir as traduções que os outros lhe apresentam das respectivas aventuras (RANCIÈRE, 2010b, p. 19).

Ainda que uma aproximação entre a pedagogia do século XIX e a dramaturgia de hoje seja um pouco obtusa, uma vez que os dramaturgos contemporâneos não se colocam numa posição de "explicar ao seu público a verdade das relações sociais e os meios de lutar contra a dominação capitalista" (RANCIÈRE, 2010b p. 20 - grifo nosso), os pressupostos de uma relação pedagógica permanecem e parecem aumentar a pressão sobre os espectadores.

[...] talvez eles, os artistas, saibam afinal o que é preciso fazer, com a condição de que a performance os tire [os espectadores] da sua atitude passiva e os transforme em participantes activos de um mundo comunitário. Esta é a primeira conviç̧ão que os reformadores do teatro partilham com os pedagogos embrutecedores: a do abismo que separa duas posições. Mesmo

17 Cf. HAMIDI-KIM Le spectateur émancipé ou la mort du théâtre critique. Propositions critiques sur Jacques Rancière In: JDEY, 2013, p. $138-139$. 
que o dramaturgo ou o realizador não saibam o que querem que o espectador faça, há pelo menos uma coisa que sabem: sabem que o espectador deve fazer uma coisa, transpor o abismo que separa atividade de passividade. (RANCIÈRE, 2010, p. 20-21 - grifo nosso)

Rancière pergunta se não é justamente a vontade de suprimir a distância que cria a distância, se não são, como afirmava alguns anos antes a respeito da sociologia, os "desmistificadores" que criam a "mistificação". Esse dever-fazer que faz da passividade um mal, que faz o tempo ser preenchido a todo instante em nome de uma atividade que sempre carregue consigo um valor positivo, não importa o que, é nosso maior desafio, tanto em educação ${ }^{18}$ quanto em política. Atividade que faz da escola uma sucessão de tempos preenchidos, que se horroriza diante dos imprevistos de lacuna, a falta de um professor, a sobra de tempo. Quando isso acontece preenche-se com alguma atividade que não deixe que o tempo livre cause algum dano, moral. Fazer, fazer, fazer: agir sempre. A passividade é um mal a ser abolido. Alienação, ideologia: termos tão caros à tradição marxista têm aqui o seu peso. ${ }^{19}$

O que é que permite declarar inactivo o espectador sentado no seu lugar a não ser a oposição radical, previamente estabelecida entre o activo e o passivo? Por que identificar olhar e passividade, senão por força do pressuposto de que olhar quer dizer comprazer-se na imagem e na aparência, ignorando a verdade que está por trás da imagem e a realidade exterior ao teatro? Por que assimilar escuta e passividade, senão por via do preconceito segundo o qual a palavra é o contrário da acção? (RANCIÈRE, 2010b, p. 21)

Antes de serem oposições lógicas são oposições policiais definidas por uma partilha do sensível que distribui a priori cada um desses lugares de acordo com a sua respectiva capacidade ou incapacidade. Como mostra Villacèque (2013), para os gregos do regime democrático ateniense, ser espectador não é símbolo de passividade, mas, ao contrário, supunha mesmo a atividade do público, uma manifestação barulhenta [thorubos] frente aos dramas. ${ }^{20} \mathrm{Ver}$, escutar, não são assim só paixões, mas já também ações. É, portanto, a partilha do sensível do regime ético das imagens, com Platão, que primeiro estabelece essa interpretação, delimita essa distribuição dos lugares da passividade e atividade, separa-as. E todas as tentativas de inversão desses lugares só mantêm a mesma estrutura de oposição em funcionamento. Não adianta transformar o mau termo em bom e vice-versa, como já demonstramos várias vezes na análise sobre o pensamento de Rancière: “o essencial está no facto de permanecer a estrutura que opõe as duas categorias, os que possuem uma dada capacidade e os que a não possuem" (RANCIËRE, 2010, p. 22). Assim os mesmos que desqualificam o espectador porque não faz nada e elogiam os atores ou os trabalhadores por colocarem seus corpos em ação podem inverter rapidamente o seu juízo quando a ação vem associada ao imediato do empírico em oposição à contemplação mais abrangente dos fatos, de uma visão mais global.

A emancipação intelectual surge, assim, como alternativa a essa lógica, uma vez que não pressupõe a distância entre incapacidade e capacidade, independente de com o que as associamos. A emancipação começa justamente quando se compreende que as evidências que "estruturam as relações do dizer, do ver e do fazer pertencem elas próprias à estrutura da dominação e da sujeição" (RANCIÈRE, 2010b, p. 22), à própria partilha do sensível, à polícia, poderíamos mesmo dizer, "quando se compreende que olhar é também uma acção que confirma ou transforma essa distribuição

18 Cf. MASSCHELEIN; SIMONS; 2014.

19 "O espetáculo é a ideologia por excelência, porque expõe e manifesta na sua plenitude a essência de todo sistema ideológico: o empobrecimento, a escravidão e a negação da vida real. O espetáculo é materialmente «a expressão da separação e da distância entre homem e homem»" (DEBORD, 1967, p. 205 - tradução nossa).)

${ }^{20}$ Cf. VILLACÈQUE, 2013, p. 268-277. 
das posições" (RANCIÈRE, 2010b, p. 22). É quando podemos ver um papel ativo no olhar do espectador e não buscamos a sua reforma, a sua transformação, que podemos enxergar que

o espectador também age, como o aluno ou o cientista. Observa, seleciona, compara, interpreta. Liga o que vê com muitas outras coisas que viu noutros espaços cénicos e noutro género de lugares. Compõe o seu próprio poema com os elementos do poema que tem à sua frente (RANCIÈRE, 2010b, p. 22 - grifo nosso).

Esse parece ser um ponto-chave, o mesmo processo da inteligência que fez a obra artística acontece naquele que a olha, mas não acontece a mesma obra, o mesmo poema. Como também não acontece a mesma aprendizagem. O pressuposto pedagogizante tanto da eficácia da mediação representativa quanto da imediaticidade ética ${ }^{21}$ é o de que há um algo idêntico que a intenção do artista transmite a todo aquele que vê, participa, de uma mesma obra sua. É o pressuposto da transmissão, da identidade de causa e efeito: "há uma certa coisa, uma capacidade, uma energia, que está de um lado - num corpo ou num espírito - e que deve passar para outro lado" (RANCIÈRE, 2010, p. 23). É a lógica da pedagogia embrutecedora, "o que o aluno deve aprender é o que o mestre lhe ensina. O que o espectador deve ver é o que o realizador lhe dá a ver. $\mathbf{O}$ que deve sentir é a energia que o realizador lhe comunica" (RANCIEERE, 2010, p. 23 - grifo nosso). ${ }^{22}$ Esse pressuposto pedagógico é também visível em várias das ações políticas de grupos. Conscientizar as massas, seja através do partido ou, mais contemporaneamente, através de think tanks, ONGs, etc., são meros reflexos da crença e da importância da ideia de pedagogia presente na relação entre sujeitos. O que a emancipação intelectual vem mostrar, no paradoxo da experiência de Jacotot, é que é possível dissociar esses dois lados da equação, que o aluno aprende do mestre algo que este não lhe ensina, pois o aprendido o mestre não sabe. Mas o paradoxo é justamente que é do mestre que ele aprende, como mostra Rancière em $L e$ Maître ignorant (1987) Sem mestre não há emancipação intelectual. ${ }^{23}$

$\mathrm{O}$ erro do pressuposto pedagogizante das eficácias da mediação representativa e da imediaticidade ética é o de confundir duas distâncias. Além da que liga artista e espectador, há "a distância inerente à própria performance na medida em que esta se encontra - enquanto espectáculo, enquanto coisa autónoma - entre a ideia do artista e a sensação ou compreensão do espectador" (RANCIĖRE, 2010b, p. 24). A performance é a terceira coisa, que no âmbito da lógica da emancipação intelectual é representada pelo livro, por Telêmaco, por exemplo.

não é a transmissão do saber ou do respirar do artista ao espectador. É antes essa terceira coisa de que nenhum deles é proprietário, da qual nenhum deles possui o sentido, essa terceira coisa que se mantém entre os dois, retirando ao idêntico toda e qualquer possibilidade de transmissão, afastando qualquer identidade de causa e efeito" (RANCIÈRE, 2010b, p. 24-25).

Esse terceiro elemento traz à emancipação intelectual uma característica distinta daquela "em que se apoiou muitas vezes a política do teatro e da respectiva reforma: a emancipação como reapropriação do sujeito a si mesmo" (RANCIÈRE, 2010, p. 28), que o sujeito tome consciência de si, das suas relações, etc., etc. Essa ideia de que um terceiro termo, a obra, não pode obstruir a linha de transmissão da mensagem do artista ao público é o que fez que se pensasse na supressão da separação entre palco e plateia da qual todas as disposições teatrais alternativas ao palco italiano, efetuadas nos últimos

\footnotetext{
${ }^{21}$ Cf. RANCIÈRE, 2008, p. 62.

${ }^{22}$ Cf. HAMIDI-KIM Le spectateur émancipé ou la mort du théâtre critique. Propositions critiques sur Jacques Rancière In: JDEY, 2013, p. 138-139.

${ }^{23}$ Cf. RANCIÈRE, 1987, p. 24-25.
} 
anos, são prova. Se essas alterações contribuíram enormemente às possibilidades da performance teatral, ${ }^{24}$ não podem se transformar num dever-ser, numa regra moral, pois

uma coisa é a redistribuição dos lugares, outra coisa é a exigência de que o teatro assuma como finalidade a reunião de uma comunidade de modo a pôr termo à separação do espectáculo [...] a primeira gera um comprometimento na invenção de novas aventuras intelectuais, ao passo que a segunda traz consigo uma nova forma de atribuição dos corpos ao seu bom lugar, que neste caso é o respectivo lugar de comunhão (RANCIÈRE, 2010, p. 26 - grifo nosso).

Uma é política, a outra policial. É preciso, portanto, desconfiar desse papel de lugar paradigmático de comunidade do teatro, de um papel eminentemente político que o teatro se outorgou. ${ }^{25}$ Rancière pergunta se já não seria tempo de nos perguntarmos sobre esse lugar comunitário do teatro. E aqui talvez devêssemos nos perguntar, também, sobre o lugar comunitário da escola.

... em rigor, o que é que se passa com os espectadores de um teatro que não pudesse passar-se noutras circunstâncias? Haverá algo de mais interactivo, de mais comunitário, nestes espectadores do que numa multiplicidade de indivíduos vendo à mesma hora o mesmo espectáculo televisionado?" (RANCIÈRE, 2010, p. 27 - grifo nosso)

O mesmo talvez pudéssemos perguntar da escola: em rigor, o que é que se passa com alunos de uma escola que não pudesse passar-se noutras circunstâncias? Haverá algo de mais interativo, de mais comunitário, nestes alunos (aprendizes) do que numa multiplicidade de indivíduos vendo à mesma hora a mesma "lição" televisionada? Essas perguntas podem parecer apenas provocações, e em certa medida o são, mas parecem-nos fundamentais para repensarmos a atualidade da democracia, uma vez que esta sempre fora comparada a esse lugar do teatro. Assim, numa época como a nossa, em que o espaço teatral e o espaço da assembleia (Boulé) não são exatamente o mesmo, como o foram algumas vezes, ${ }^{26}$ perguntar pelo que difere o teatro como lugar comunitário de outros lugares, como o público de televisão (ou mesmo de internet, das redes sociais, da literatura, cinema, etc.), é perguntar justamente pelo espaço e se há verdadeiramente um espaço para a democracia, um espaço próprio, necessário para a democracia, para a vida em comum. Em suma, por que privilegiar um espaço comunitário a despeito de outros? O mesmo se poderia dizer a respeito da educação, por que privilegiar apenas a escola como $o$ espaço comunitário de aprendizagens em detrimento de outros?

$O$ poder comum dos espectadores nada tem a ver "com a respectiva qualidade de membros de um corpo colectivo ou com qualquer forma específica de interactividade" (RANCIÈRE, 2010b, p. 26). A comunidade não nos dá nenhum tipo de poder, esse poder comum é "antes o poder que cada um e cada uma tem de traduzir à sua maneira o que percebe, de ligar o que percebe à aventura intelectual singular que os torna semelhantes a todos os outros na medida em que essa aventura não se assemelha a nenhuma outra" (RANCIÈRE, 2010b, p. 27). É, portanto, a semelhança do dessemelhante que nos dá a todos esse poder comum. Assim, "o que as nossas performances comprovam - quer se trate de ensinar ou representar, de falar, de escrever, de fazer arte ou vê-la - não é a nossa participação num poder encarnado da comunidade" (RANCIÈRE, 2010, p. 27-28 - grifo nosso). Ao invés, portanto, desse poder de redenção religiosa do todo que a comunhão teatral propõe, passível de elogios e críticas de ambos os espectros políticos, a depender da distância da totalidade (unidade) desejada,

\footnotetext{
${ }^{24}$ Cf. RANCIÈRE, 2008, p. 21.

${ }^{25}$ Cf. RANCIÈRE, 2009, p. 627.

${ }^{26}$ Cf. VILLACÈQUE, 2013, p. 138-151
} 
mais vale pensarmos a partir da capacidade de não-importa quem, ${ }^{27}$ dos anônimos. É "a capacidade dos anónimos, a capacidade que faz com que cada um(a) seja igual a todos(as) os(as) outros(as)" (RANCIÈRE, 2010b, p. 28), que se exerce através de um jogo imprevisível de associações e dissociações o que merece ser, por nós, melhor pensada. É essa capacidade dos anônimos, do qualquer um, o que nos faz comum, a partir do qual a política é possível e, a partir do qual, a democracia não constitui apenas um regime de poder. É isso que o governo, o comando (kratos) do démos significa, a indiferença de qualquer um, qualquer um pode mandar. A radicalidade dessa ideia, tanto para a política, quanto para a educação, em especial aos nossos atuais sistemas de educação, é, de longe, um dos nossos maiores obstáculos em nossas vidas democráticas, em nossas sociedades democráticas.

Ser um espectador emancipado reside nisso. A emancipação do espectador é esse poder de associar e dissociar: "não é a condição que devêssemos transformar em atividade. É a nossa situação normal. Aprendemos e ensinamos, agimos e conhecemos também enquanto espectadores que ligam constantemente o que vêem com aquilo que já viram e disseram, fizeram e sonharam" (RANCIÈRE, 2010 b, p. 28 - grifo nosso). É um saber-ignorante que nos constitui desde o momento em que somos lançados neste mundo. Nossa tarefa, assim, nas artes, na educação, não advém de transformar espectadores em atores e ignorantes em cientistas. Isso já é uma ação institucional, policial, marcada numa certa partilha do sensível.

A quem pretenda uma ação crítica, que desloque, portanto, “o equilíbrio dos possíveis e a distribuição das capacidades" (RANCIÈRE, 2010b, p. 122) é preciso três recusas principais das partilhas do sensivel pedagógicas: "em primeiro lugar, a distância radical, em segundo lugar, a distribuição dos papéis, e em terceiro lugar, as fronteiras entre os territórios" (RANCIĖRE, 2010b, p. 28). A distância radical e a distribuição dos papeis que o regime ético das imagens nos legou, que nos afirma que são de natureza diferentes aquele que sabe e aquele que não sabe. A questão do mestre/professor, portanto. $\mathrm{E}$ as fronteiras entre os territórios que o regime representativo da arte nos deixou, que nos diz que as coisas são próprias ou impróprias se seguirmos a legislação específica de cada arte e de cada saber, que hierarquiza assim os níveis de discurso, que abole a contradição por meio da "higienização" da linguagem. Questão de lição, portanto. Recusados esses princípios, quem sabe, possamos reconhecer que "todo o espectador é já actor da sua história; todo actor, todo o indivíduo de acção, é já espectador da mesma história” (RANCIÈRE, 2010b, p. 28).

Esse reconhecimento não se presta a uma diluição de um lugar no outro, mas à recusa de ver a primazia de um sobre outro, de ver uma diferença que permita buscar a supressão de um lugar a outro, de abolir a distância que os liga e os separa. O lugar, assim, da educação não é um lugar que tende ao seu esvanecimento, que tende a uma igualdade. Ele já é igual e diferente ao mesmo tempo, ele já pressupõe uma igualdade na diferença, na diferença de lugares. O lugar de mestre e o lugar de aluno não se dissipam, mas eles não se baseiam mais numa diferença de inteligências. É a mesma inteligência que opera nos dois lugares, que nos faz a todos espectadores-atores, atores-espectadores. $\mathrm{Ou}$, se quiserem, sábios-ignorantes, ignorantes-sábios.

A reforma do espectador para salvar o teatro, assim como a tão-falada reforma do aluno para salvar a escola, que, via de regra, se dá pelas mudanças nas metodologias pedagógicas, ou seja, no modo como se enxerga o aluno e seu aprendizado, independente do que esses conceitos queiram indicar a

\footnotetext{
27 "Penso que é preciso sair da alternativa entre os grandes sujeitos coletivos do tipo «proletariado» e os indivíduos e as combinações de suas estratégias individuais. Pela minha parte, não estava interessado em criticar Bourdieu por contribuir a uma teoria dos atores racionais individuais. Para mim, o problema geral é o da capacidade de não importa quem. Essa capacidade se concretiza sempre sob formas coletivas. Não se pode nunca pensar a política como simples combinação das atitudes individuais. $\mathrm{O}$ que há a pensar não são os grandes sujeitos ou os pequenos atores, mas sim a constituição concreta da capacidade de não importa quem: isso implica a ação dos coletivos, os quais repousam, certamente, sobre os indivíduos dotados de capacidades de pensar o mundo por si mesmos. Mas a política tem isso de específico, invocar as formas de enunciação coletiva" (RANCIÈRE, 2009, p. 582 - tradução nossa).
} 
cada momento e em cada contexto, tende a reforçar a ideia de que o que espectadores e alunos são só pode ser permitido por um estatuto de dever-ser, por imperativos morais. Como lugares de passividade são arriscadamente sujeitos à ilusão e devem ser ensinados, submetidos à relação de maestria. É sempre, portanto, uma moralidade a ditar o ritmo e os objetos de uma educação.

Ser ensinado, antes de significar aprender, significa: há alguma coisa em mim que precisa ser melhorada, transformada, consertada. Governada e tutelada. Significa: se deixado ao léu corro riscos sociais, de sobrevivência, etc. E só pode ensinar aquele que conhece a distância que liga a ignorância à sua supressão. Estamos diante de uma relação de embrutecimento e, não, de emancipação. Para que esta ocorra, é preciso que dissociemos a figura do espectador de sua conotação ética e a deixemos tão somente em seu aspecto estético. A emancipação é pensada, agora, não mais como um saber, mas como aquilo que a palavra significa, isto é, o desmantelamento da "fronteira entre os que agem e os que vêem, entre indivíduos e membros de um corpo colectivo" (RANCIÈRE, 2010b, p. 31).

Não se tratava, por exemplo, nos relatos operários do século XIX, de "um saber acerca da sua condição e a energia necessária para o trabalho da semana seguinte ou para a luta subsequente" (RANCIÈRE, 2010b, p. 31), mas antes de uma reconfiguração do espaço e do tempo, do trabalho e do ócio. Não se tratava de uma tarefa, por sinal interminável, de reduzir um afastamento irredutível, mas de compreender a rotura no interior do tempo daqueles operários e desenvolver as implicações da semelhança e da igualdade ali presentes. Para o filósofo francês, aqueles operários “eram, também eles, intelectuais, como qualquer pessoa o é” (RANCIÈRE, 2010b, p. 31).

Não há mais, portanto, aqui a separação entre dois personagens da tradição marxista, o intelectual e o trabalhador. Também os trabalhadores "eram visitantes e espectadores, como o investigador [Rancière] que, um século e meio mais tarde, lia as cartas numa biblioteca, como os visitantes da teoria marxista ou os indivíduos que distribuíam panfletos à porta das fábricas" (RANCIÈRE, 2010, p. 32). Não havia, portanto, "nenhuma brecha para ser colmatada entre intelectuais e operários, como não existe entre actores e espectadores" (RANCIÈRE, 2010, p. 32). Sem a distância intelectual, portanto, da relação pedagógica, um outro pensamento pode desde aí surgir. A política e a arte não necessitam da desigualdade, poderíamos dizer. Deveríamos nos perguntar, então, se a educação também não.

\section{REFERÊNCIAS}

ARTAUD A. O teatro e seu duplo. São Paulo: Martins Fontes, 1999

CASSIN, B. O efeito sofistico: sofistica, filosofia, retórica, literatura. São Paulo: Ed. 34, 2005.

CICERO De haruspicum responsis $(11,22)$ In: PERSEUS DIGITAL LIBRARY. Disponível em: http://www.perseus.tufts.edu/hopper. Acesso em: 10 nov. 2019.

De Natura deorum librii In: PERSEUS DIGITAL LIBRARY. Disponível em: http://www.perseus.tufts.edu/hopper. Acesso em: 10 nov. 2019.

De officis (2, 7, 26) In: PERSEUS DIGITAL LIBRARY. Disponível em: http://www.perseus.tufts.edu/hopper. Acesso em: 10 nov. 2019.

De oratore $(1,24,112)$ In: PERSEUS DIGITAL LIBRARY. Disponível em: http://www.perseus.tufts.edu/hopper. Acesso em: 10 nov. 2019.

DEBORD, G. La société du spectacle. Paris: Éditions Buchet-Chastel 
ERNOUT, A.; MEILLET, A. Dictionnaire étymologique de la langue latine. Histoire des mots. Paris: Librairie C. Klincksieck, 1959.

FREIRE. P. Pedagogia do oprimido. Rio de Janeiro: Paz e Terra, 1982.

GODZICH, W. Prefácio In: DE MAN, P. A resistência à teoria, Lisboa: Edições 70, 1989.

HAMIDI-KIM, B. Le spectateur émancipé ou la mort du théâtre critique. Propositions critiques sur Jacques Rancière In: JDEY, A. Politiques de l'image. Questions pour Jacques Rancière. Bruxelles: La lettre volée, 2013

KANT, I. O conflito das faculdades Covilhã: Universidade da Beira Interior, 2008.

MASSCHELEIN, M.; SIMONS, M. A pedagogia, a democracia, a escola. Belo Horizonte: Autêntica, 2014.

MONTAIGNE, M. Ensaios. São Paulo: Abril cultural, 1972.

PLAUTO. Anfitrião In: PLAUTO. Comédias. Lisboa: INCM, 2006.

Cistellaria. Paris: Les Belles Lettres, 2003.

Pseudolus. Paris: Les Belles Lettres, 1957.

Stichus. Paris: Les Belles Lettres, 1962.

PLATÃO. As leis, ou da legislação e epinomis. São Paulo: Edipro, 2010.

RANCIÈRE, J. Aisthesis: Scènes du régime esthétique de l'art. Paris: Galilée, 2011.

A noite dos proletários. Arquivos do sonho operário. Lisboa: Antígona, 2012.

A partilha do sensivel. Estética e política. Porto: Dafne editora, 2010a.

Bela Tarr, le temps d'après. Nantes: Capricci Éditions, 1996.

École, production, égalité In: RENOU, X. L'école de la démocratie. Paris: Edilig, Fondation Diderot, 1988.

Et tant pis pour les gens fatigués. Entretiens. Paris: Éditions Amsterdam, 2009.

La chair des mots. Politique de l'écriture. Paris: Galilée, 1998a.

La fable cinématographique. Paris: Seuil, 2001.

La methode de l'égalité: Entretien avec Laurent Jeanpierre et Dork Zabunyan.

Paris: Bayard, 2012.

La mésentente. Paris: Galilée, 1995.

Littérature, 1998b.

La parole muette. Essai sur les contradictions de la littérature. Paris: Hachette Paris: Horlieu, 2006.

La philosophie deplacée. Autour de Jacques Rancière. Actes du colloque de Cerisy. Le destin des images. Paris: La Fabrique, 2003a.

1987.

Le maître ignorant: Cinq leçons sur l'émancipation intellectuelle. Paris: Fayard, Le partage du sensible: Esthétique et politique. Paris: La Fabrique, 2000.

Les écarts du cinema. Paris: La Fabrique, 2011.

Le spectateur émancipé. Paris: La Fabrique, 2008.

R. Inter. Interdisc. Art\&Sensorium, Curitiba, v.7, n.1, p. 028 - 043 Jan.- Jun. 2020 
Les scènes du peuple. Les <Révoltes logiques>, 1975-1985. Paris: Horlieu, 2003b. Malaise dans l'esthétique. Paris: Galilée, 2004.

Mallarmé: La polique de la sirene. Paris: Hachette Littérature, 1996.

Moments politiques - Interventions 1977-2009. Paris: La Fabrique, 2009.

O destino das imagens. Lisboa: Orfeu negro, 2011.

$\overline{\text { Autêntica, } 2005 \text {. }}$

O mestre ignorante. Cinco lições sobre a emancipação intelectual. Belo Horizonte:

O espectador emancipado. Lisboa: Orfeu negro, 2010 b.

RANCIÈRE, J. ; FAURE, A. La parole ouvrière. Paris: La Fabrique, 2007.

REY, A. (org.) Dictionnaire historique de la langue française. Paris: Le Robert, 1992.

TITO-LÍVIO Ab urbe condita libri In: PERSEUS DIGITAL LIBRARY. Disponível em: http://www.perseus.tufts.edu/hopper. Acesso em 20 nov. 2019.

VILLACÈQUE, N. Spectateurs de paroles! Déliberation démocratique et théâtre à Athènes à l'époque classique. Rennes: Presses Universitaires de Rennes, 2013. 